\title{
Ketidakharmonisan Keluarga Terhadap Tindakan Sosial dan Spiritual Remaja di Youth GBI Eben Haezer
}

\author{
Ibnu Salman ${ }^{1}$, Onnie Lumintang², Yada Putra Gratia ${ }^{3}$, Sewi Anastasya \\ Simamora ${ }^{4}$ \\ ${ }^{1}$ Litbang Kementrian Agama Republik Indonesia \\ 2,3,4 Sekolah Tinggi Teologi Bethel Indonesia \\ ibnusalman81@kemenag.go.id, onnie.lumintang@sttbi.ac.id, \\ yadaputra@sttbi.ac.id., anastasyasimamora94@gmail.com
}

\begin{abstract}
Abstrak
Masalah kenakalan remaja dewasa ini semakin meresahkan masyarakat terkhusus di kota kosmopolitan seperti Jakarta. Negara-negara yang maju maupun negara yang sedang berkembang juga merasakan keresahan karena kenakalan remaja yang semakin pesat terjadi yang membawa dampak buruk dalam kehidupan sosial masyarakat. Sebut saja masalah pemberontakan terhadap orang tua, seks bebas, merokok, dan minuman berarkohol yang memabukkan. Masalah ini juga merambah ke dalam remaja gereja yang hidup bersama dengan masyarakat secara luas. Akar dari masalah ini adalah keutuhan dan keharmonisan keluarga dalam mendidik anak sesuai Firman Tuhan. Penelian ini bertujuan untuk mengkaji pengaruh disharmonis dalam keluarga bagi kehidupan sosial dan spiritual anak muda. Metode yang digunakan adalah kuantitatif dengan variabel $\mathrm{Y}$ adalah kehidupan sosial dan spiritual remaja Masterplan Youth GBI Eben Heazer. Hasil penelitian menunjukkan bahwa pengaruh ketidakharmonisan keluarga berada pada kategori sangat rendah. Artinya ketidakharmonisan keluarga tidak terlalu berpengaruh besar pada kehidupan sosial dan spiritual remaja. Kenakalan remaja yang terjadi bisa saja karena dipengaruhi oleh faktor lain seperti dari keadaan ekonomi, lingkungan atau bisa dari faktor individu itu sendiri.
\end{abstract}

Kata Kunci: Ketidakharmonisan, Keluarga, Sosial-spiritual, GBI Eben Haezer

\begin{abstract}
The problem of juvenile today is increasingly troubling the community, especially in a cosmopolitan city like Jakarta. Developed countries as well as developing countries also feel uneasy because juvenile delinquency is increasingly occurring which has a negative impact on people's social life. Call it the problem of rebellion against parents, free sex, smoking, and intoxicating alcoholic drinks. This problem also extends to the youth of the church who live together with society at large. The root of this problem is the wholeness and harmony of the family in educating
\end{abstract}


children according to God's Word. This study aims to examine the effect of disharmony in the family on the social and spiritual life of young people. The method used is quantitative with the Y variable being the social and spiritual life of the youth of the Masterplan Youth GBI Eben Heazer. The results showed that the effect of family disharmony was in the very low category. This means that family disharmony does not have a big influence on the social and spiritual life of adolescents. Juvenile delinquency that occurs can be influenced by other factors such as economic conditions, the environment or it can be from individual factors themselves.

Keywords: Disharmony; Family; Socio-spiritual; GBI Eben Haezer 


\section{PENDAHULUAN}

Masalah kenakalan remaja dewasa ini semakin meresahkan masyarakat di kota-kota besar dan juga di pedesaan. Beberapa faktor yang dapat memicu terjadinya kenakalan remaja seperti mentalitas yang ingin mengetahui banyak hal tentang dunia dan pencarian identitas diri pada fase pubertas dari masa kanak-kanak menuju kepada kedewasaan (Hidajahturrokhmah et al., 2018). Selain itu, faktor keluarga juga menjadi faktor terjadinya tindakan sosialspiritual yang negatif (Cipta, 2017).

Paham kenakalan remaja dalam arti luas, meliputi perbuatan anak remaja yang bertentangan dengan kaidah-kaidah hukum tertulis baik yang terdapat dalam KUHP (pidana umum) maupun perundangundangan di luar KUHP (pidana khusus), dapat pula terjadi perbuatan anak remaja tersebut bersifat anti sosial yang menimbulkan keresahan masyarakat pada umumnya. Contoh sederhana mengenai kenakalan remaja antara lain yaitu, merokok, pencurian oleh remaja, perkelahian dikalangan pelajar yang kerap kali berkembang menjadi tawuran antar sekolah, menggangu wanita dijalanan dimana pelakunya adalah seorang anak yang masih remaja, memberontak terhadap orang tua, perbuatan tercela pornografi, merusak fasilitas lingkungan sekitar dan tidak memiliki sopan santun di lingkungan masyarakat (Sumara et al., 2017). Kategori usia dikatakan remaja adalah berumur 21 tahun.

Perilaku kenakalan remaja tidak hanya mencakup tindakan kriminal atau pemakaian obat-obatan terlarang saja, namun perilaku penyimpangan lainnya juga berupa pelanggaran status yang dilakukan oleh anak, norma maupun pelanggaran terhadap hukum. Maksud dari pelanggaran status yang dilakukan oleh anak contohnya yaitu, seperti kabur dari rumah, tidak masuk sekolah, meminum minuman keras, kebut-kebutan dijalan dan lain sebagainya. Kenakalan remaja lain, yang juga semakin meresahkan adalah perilaku konsumsi miras. Riset dari Gerakan Nasional Anti Miras (Genam) menunjukkan adanya lonjakan drastis dari jumlah remaja pengonsumsian miras di Indonesia. Tahun 2014 tercatat, angka konsumsi miras remaja mencapai 23 persen dari total jumlah remaja Indonesia yang saat ini berjumlah 63 juta jiwa atau sekitar 14,4 juta orang (Winurini, 2018). Sedangkan perilaku yang menyimpang terhadap norma seperti halnya seks pranikah dikalangan remaja, dan aborsi yang dilakukan oleh remaja wanita. Jumlah perilaku penyimpangan tersebut mengalami 
peningkatan yang cukup pesat dari tahun ke tahun (Rahmajati, 2018).

Kasus-kasus kenakalan anak pun lambat laun telah merambah ke area kriminal yang lebih tinggi. Catatan kasus penyalahgunaan Napza yang merupakan akronim dari narkoba, Psikotropika dan zat adiktif lainnya yang merupakan jenis obatobatan berbahaya yang dapat mempengaruhi gangguan kesehatan dan kejiwaan tahun 2017 Deputi Bidang Rehabilitasi BNN, dari kelompok usia 15-25 tahun terdata 1.210 kasus pernyalahguna Napza ditahun 2018 (Puslidatin, 2019). Jumlah ini kiranya hanya merepresentasikan sebagian kecil kasus yang secara nyata ada di Indonesia.

Meningkatnya kenakalan remaja dari waktu kewaktu semakin mengalami peningkatan frekuensi yang cukup signifikan. Hal ini akan merugikan bangsa Indonesia karena remaja saat ini adalah pemimpin pada saat Indonesia berada pada bonus demograi tahun 2025, oleh karena itu, permasalahan ini harus segera ditanggulangi dengan cepat secara bersama-sama agar tidak semakin meningkatnya jumlah kenakalan remaja (Aviyah \& Farid, 2014).

Remaja nakal rata-rata hanya berorientasi pada masa sekarang, berfoyafoya memenuhi hasrat kesenangannya sendiri tanpa memikirkan akibat dari apa yang dilakukannya di masadepannya. Kebanyakan dari mereka terganggu secara emosional. Mereka kurang bersosialisasi dengan masyarakat normal disekitar mereka, sehingga tidak bertanggung jawab secara sosial, senang menjerumuskan diri dalam hal yang tidak baik tanpa berpikir secara sehat terlebih dahulu. (Muniriyanto,Suhaman, 2014)

Remaja merupakan generasi penerus bangsa yang diharapkan dapat menggantikan generasi-generasi terdahulu dengan kualitas kinerja dan mental yang lebih baik untuk memajukan kesejahteraan bangsa. Banyaknya jumlah remaja di Indonesia tentu saja akan menjadi aset yang sangat berharga bagi negara jika remaja tersebut memperlihatkan potensi diri yang positif karena kelak remaja tersebutlah yang akan meneruskan kemajuan bangsa ini, namun sebaliknya akan menjadi masalah besar bagi bangsa ini jika remaja tersebut memperlihatkan perilaku yang negatif bahkan sampai melakukan perilaku-perilaku menyimpang yang melanggar norma (Sirait, 2021).

Faktor lingkungan yang buruk seperti masyarakat yang terbiasa hidup dengan melakukan kekerasan, terbiasa dengan pergaulan bebas, terbiasa merokok, sehingga dapat memberikan pengaruh buruk 
terhadap remaja ke dalam hal-hal yang tidak baik, atau faktor dari individu itu sendiri dimana ia kurang memiliki pengendalian diri yang baik sehingga orientasi sikap yang ia milikipun rendah. Contoh perilaku kenakalan yang biasa dilakukan oleh remaja yaitu, merokok atau nge-vape, memberontak atau dapat dikatakan juga suka tawuran, melakukan seks bebas dan memakai obatobatan terlarang (narkoba). Tingkah laku menyimpang dalam sosial dan spiritual inilah yang sering dikatakan sebagai kenakalan remaja.

Selain lingkungan, keluarga memainkan peran vital dalam memupuk kecerdasan sosial dan spiritual remaja. Tetapi, jika hubungan orangtua tidak harmonis, maka cita-cita tersebut sulit untuk terwujud. Yang penulis maksudkan dengan disharmonis adalah keadaan dimana orang tua tidak menjalankan fungsinya dengan baik untuk mendidik anaknya dan pertengkaran yang dilihat secara langsung oleh sang anak dapat membuat anak tidak nyaman berada dirumah, sehingga tidak sedikit anak remaja korban dari hubungan orangtua mereka yang tidak harmonis lebih memilih bersenangsenang dan menghabiskan waktu diluar rumah. Remaja merasa apa yang menjadi kebutuhan atau keinginannya tidak dapat terpenuhi dari orangtuanya, baik itu kebutuhan dalam hal materi ataupun kebutuhan psikis seperti kasih sayang dan perhatian, sehingga remaja mencari cara sebagai jalan keluar agar mereka bisa mendapatkan apa yang mereka butuhkan (Nadya Paramitha et al., 2019). Ketidakharmonisan keluarga di dalam rumah tangga akan sangat mempengaruhi tumbuh kembang seorang anak remaja, perkembangan mental anak dan karakter anak.

Orang tua akan sedih ketika anaknya jatuh di dalam pergaulan yang salah. Hal ini selalu menjadi masalah yang selalu memusingkan para orangtua adalah keterlibatan mereka dalam berbagai tindak kriminal (Zakiyyah, 2019). Jika para remaja sudah terlibat tindak kriminal, maka persoalan ini tidak lagi bisa dipandang sebagai hanya kenakalan biasa yang lazim terjadi dikalangan para remaja, melainkan perilaku yang sudah mengarah pada tindak kejahatan pidana. Dalam kenyataan kehidupan sehari-hari faktanya menunjukkan bahwa semakin meningkatnya jumlah remaja yang terlibat dalam berbagai jenis kenakalan remaja seperti tindak kriminal yang menimbulkan keresahan sosial terhadap masyarakat sekitar (Een et al., 2020). Tindakan sosial yang menyimpang ini 
disebut oleh para ahli sebagai delikuensi (Noegroho, 2016).

Perilaku delinkuensi adalah suatu perilaku menyimpang yang dilakukan oleh seorang anak remaja yang secara hukum sosial di masyarakat dikategorikan sebagai suatu tindakan kriminal yang melanggar hukum dan norma yang berlaku. Apabila yang melakukan tindakan menyimpang tersebut adalah orang dewasa maka dapat dikatakan ia adalah pelaku kejahatan yang harus dikenakan sanksi tindak pidana, dan apabila yang melakukan tindakan tersebut adalah seorang anak remaja dapat dikatakan bahwa itu adalah perilaku kenakalan remaja (Hadisuprapto, 2010). Remaja menjadi pengguna media sosial yang tinggi di era digitalisasi, dan imbas dari hal tersebut dapat menyebabkan disrupsi dalam hal kehidupan sosial yang berujung pada perilaku remaja (Benyamin et al., 2021). Selain itu masa pandemi yang masih terus berlangsung, memberikan kesempatan bagi remaja mengunakan media teknologi untuk belajar (Salman et al., 2021). Di satu sisi, teknologi membantu remaja belajar online, disisi lain membuka kesempatan cyberbullying makin besar. Permasalahan kenakalan remaja ini bagaikan benang kusut yang sedang tarik menarik untuk dapat terurai, sebab fenomenanya telah merambah dalam institusi agama, yakni gereja.

Kenakalan remaja yang terjadi di Masterplan Youth GBI Eben Haezer ini meliputi seks bebas, pemberontakan, baik itu memberontak dalam lingkungan sosial ataupun dalam keluarga terhadap kedua orangtuanya, mengkonsumsi minumminuman keras. Data ini peneliti peroleh dari hasil pra-wawancara dengan para pemimpin Masterplan Youth. Tentu gereja tidak boleh berdiam dalam menghadapi realitas ini. Gereja harus melakukan pelayanan holistik agar remaja kedepannya dapat menjadi penerus dari gereja dan bangsa (Trisna, 2016). Berbagai upaya dilakukan, mulai dari konseling (Johni Hardori, 2014), penyampaian firman yang kreatif dan relevan tanpa menghilangkan esensi (Christi, 2018), bahkan pengajaran atau pemuridan yang mempertemukan antara perjumpaan dengan dogmatika (Amos Hosea, 2019). Tindakan gereja ini tentunya harus dibarengi dengan semangat dan peran dari orang tua sebagai unit terdekat dan terkecil si anak. Fenomena ini menjadi alarm yang membangunkan orang tua untuk lebih giat dalam mendidik anak layaknya pendidikan dalam Alkitab (Pakpahan, 2020). Hal ini menyadarkan kita semua bahwa betapa pentingnya peran orangtua dan peran gereja bagi anak remaja, 
dan gereja pun perlu memberikan perhatian lebih lagi terkhusus kepada remaja yang memiliki latar belakang keluarga yang kurang baik.

Berdasarkan uraian diatas, maka penting dilakukan penelitian untuk mengetahui seberapa besar pengaruh tingkat ketidakharmonisan keluarga terhadap kenakalan remaja yang menyebabkan penyimpangan sosial-spiritual remaja di Youth Masterplan GBI Eben Heazer.

\section{METODE}

Metode penelitian yang digunakan adalah penelitian Asosiatif Causal (hubungan sebab akibat. Penelitian Asosiatif adalah penelitian yang dilakukan untuk mengetahui hubungan sebab-akibat yaitu hubungan yang bersifat mempengaruhi antara dua variabel atau lebih (Sugiyono, 2013). Adapun penelitian ini bertujuan untuk mengetahui pengaruh antara dua variabel yaitu pengaruh ketidakharmonisan keluarga (X) terhadap kenakalan remaja (Y). Untuk dapat mengidentifikasi masalah tersebut, penulis melakukan studi pendahuluan terhadap objek yang diteliti yaitu dengan cara melakukan observasi, selanjutnya dilakukan penyebaran angket kepada remaja di Masterplan Youth GBI Eben Haezer.

Penulis mengadakan penelitian di Youth GBI Eben Haezer yang beralamat di Jl.K.H.
Wahid Hasyim No.67 Jakarta Pusat. Pemilihan lokasi penelitian karena terdapat penyimpangan perilaku yang juga terjadi atau di alami oleh remaja di Masterplan Youth GBI Eben Haezer. Pengambilan data atau sampel dalam penelitian ini menggunakan teknik probability sampling yang berarti teknik sampling yang memberikan peluang yang sama bagi setiap unsur (anggota) populasi untuk dipilih menjadi anggota sampel, dengan jenis "sampel random sampling" yaitu pengambilan anggota sampel dari populasi yang dilakukan secara acak tanpa memperhatikan strata yang akan diambil dari populasi (Zaluchu, 2020).

Dalam penelitian ini, teknik pengumpulan data yang digunakan penulis adalah model skala data likert yang digunakan untuk mengukur sikap, pendapat dan persepsi seseorang atau sekelompok tentang kejadian atau gejala sosial. Dengan menggunakan skala likert, maka variabel yang akan diukur dijabarkan menjadi dimensi. Dimensi dijabarkan menjadi indikator-indikator yang dapat diukur, akhirnya indikator-indikator yang terukur ini dapat dijadikan titik tolak untuk membuat ítem instrumen yang berupa pernyataan atau pertanyaan yang perlu dijawab responden 
dengan memberi tanda cek list pada kolom yang tersedia.

Untuk melakukan uji hipotesis maka dilakukan dengan tahap-tahap sebagai berikut: (1) mendeskripsikan data untuk setiap variabel penelitian, (2) melakukan uji persyaratan analisis, dan (3) menguji hipotesis. Deskripsi data setiap variabel meliputi: pembuatan distribusi frekuensi variabel, histogram data kelompok, perhitungan mean, median, modus, standar deviasi, deskripsi setiap butir dan kecendrungan setiap variabel. Hal-hal tersebut di atas disebut dengan analisis deskriftif. Sesudah analisis deskriftif dilanjutkan dengan analisis inferensial, digunakan untuk menguji hipotesis penelitian yang meliputi analisis $\mathrm{T}$ test satu sampel, regresi sederhana dan korelasi sederhana. Sebelum melaksanakan analisis inferensial terlebih dahulu dilakukan uji persyaratan analisis yaitu uji normalitas. Dalam analisis ini digunakan program komputer yaitu Excel dan SPSS 25.0 for Windows.

\section{HASIL DAN PEMBAHASAN}

Pada bagian ini peneliti hendak menyajikan hasil penelitian pengaruh keharmonisan keluarga terhadap prilaku sosial-spiritual remaja Youth Masterplan
GBI Eben Heazer dengan aplikasi analisis SPSS 25.0 for Windows.

\section{Hasil Penelitian}

Jumlah data yang digunakan sebanyak 51 dan tidak ada data yang tidak digunakan dalam perhitungan. Selain itu diperoleh nilai rata-rata (mean) adalah 28,29, nilai median adalah 28,00, nilai modus (mode) adalah 28, standar deviasi (Std. Deviasi) adalah 2,283 varians (variance) adalah 5,212, nilai range (rentang skor) adalah 9, nilai minimum adalah 23 , nilai maksimum (maximum) adalah 32 dan nilai sum atau jumlah adalah 1443.

Rentang skor empiris dari variabel ketidakharmonisan keluarga (X) adalah 23 sampai 32, sedangkan skor teoritisnya adalah 9 sampai 36 untuk mengetahui distribusi frekuensi data penelitian digunakan rumus sebagai berikut:

Terlebih dahulu perlu dicari Skor Teoritis Maksimal dan Skor Teoritis Minimal Skor Teoritis Maksimal $=$ Nilai Maksimum Interval x Jumlah Item

$$
\begin{aligned}
& =4 \times 8 \\
& =32
\end{aligned}
$$

Skor Teoritis Minimum = Nilai minimum Interval $\mathrm{x}$ Jumlah Item

$$
\begin{aligned}
& =1 \times 8 \\
& =8
\end{aligned}
$$


Jumlah Kelas $=4$ (Sangat Setuju, Setuju,

Tidak Setuju, Sangat Tidak Setuju)

Jarak Interval $=\underline{\text { Skor Teoritis Maksimal }-}$

$\underline{\text { Skor Teoritis Minimal }}$

Jumlah Kelas

$=\underline{32-8}$

$$
4=6
$$

Jumlah data yang digunakan sebanyak 51 dan tidak ada data yang tidak digunakan dalam perhitungan. Selain itu diperoleh nilai rata-rata (mean) adalah 36,12. Nilai median adalah 36 , nilai modus (mode) adalah 35, standar deviasi (Std. Deviation) adalah 4,36, varians (variance) adalah 19,02, nilai range (rentang skor) adalah 17, nilai minimum adalah 27, nilai maksimum (maximum) adalah 44 dan nilai sum atau jumlah adalah 1842.

Rentang skor empiris dari variabel kenakalan remaja (Y) adalah 27 sampai 44, sedangkan skor teoritisnya adalah 9 sampai 44 untuk mengetahui distribusi frekuensi data penelitian digunakan rumus sebagai berikut:

Terlebih dahulu perlu dicari Skor Teoritis Maksimal dan Skor Teoritis Minimal

Skor Teoritis Maksimal $=$ Nilai Maksimum Interval x Jumlah Item

$$
=4 \times 11
$$

$$
=44
$$

Skor Teoritis Minimum = Nilai minimum Interval x Jumlah Item

$$
\begin{aligned}
& =1 \times 11 \\
& =11
\end{aligned}
$$

Jumlah Kelas $=4$ (Sangat Setuju, Setuju, Tidak Setuju, Sangat Tidak Setuju)

Jarak Interval $=\underline{\text { Skor Teoritis Maksimal }-}$ $\underline{\text { Skor Teoritis Minimal }}$

Jumlah Kelas

$=\underline{44-11}$

4

$$
=8,25=9
$$

Jumlah data yang digunakan sebanyak 51 dan tidak ada data yang tidak digunakan dalam perhitungan. Selain itu diperoleh nilai rata-rata (mean) adalah 27,63, nilai median adalah 28, nilai modus (mode) adalah 29, standar deviasi (Std. Deviation) adalah 3,94, varians (variance) adalah 15.55 , nilai range (rentang skor) adalah 23, nilai minimum adalah 12, nilai maksimum (maximum) adalah 35 dan nilai sum atau jumlah adalah 3924.

Rentang skor empiris dari variabel Ketidakharmonian keuarga (Y) adalah 12 sampai 35, sedangkan skor teoritisnya adalah 7 sampai 35.

Berdasarkan pengujian normalitas untuk variabel ketidakharmonisan keluarga (x) 
sebesar 0,027 oleh karena itu nilai probabilitas variabel lebih kecil dari taraf signifikan $\alpha=.027$, maka data variabel ketidakharmonisan keluarga berdistribusi normal.dan untuk variabel Kenakalan Remaja sebesar 0,143 . Oleh karena nilai probabilitas variabel (X) lebih kecil dari taraf signifikan $\alpha=.143$, maka data variabel Kenakalan Remaja berdistribusi normal.

\section{Analisis kelinieran variabel Ketidak Harmonisan Keluarga (X) terhadap Kenakalan Remaja (Y)}

Tabel 1. Dependent Variable: Kenakalan Remaja

\begin{tabular}{|c|c|c|r|r|r|r|r|}
\hline & \multicolumn{5}{|c|}{ Model Summary } & \multicolumn{2}{c|}{$\begin{array}{c}\text { Parameter } \\
\text { Estimates }\end{array}$} \\
\cline { 2 - 8 } $\begin{array}{c}\text { Eq } \\
\text { uan }\end{array}$ & $\begin{array}{c}\mathrm{R} \\
\text { Square }\end{array}$ & $\mathrm{F}$ & $\mathrm{df1}$ & $\mathrm{df} 2$ & Sig. & $\begin{array}{c}\text { Consta } \\
\mathrm{nt}\end{array}$ & $\mathrm{b} 1$ \\
\hline $\begin{array}{c}\text { Lin } \\
\text { ear }\end{array}$ & .092 & 4.981 & 1 & 49 & .030 & 19.697 & .580 \\
\hline
\end{tabular}

Uji linearitas dihitung dengan uji galat regresi linear atau uji linearitas atas penyimpangan (deviation from linearity) antara ketidakharmonisan keluarga (X) terhadap variabel kenakalan remaja (Y)

Berdasarkan koefisien korelasi antara X terhadap Y sebesar 0,304 termasuk dalam kategori sangat rendah. Jadi, dapat dihasilkan signifikan value sebesar 0,030 . Karena $\mathrm{p}<\alpha$, yaitu $0,000<0,05$, maka hubungan antara variabel ketidakharmonisan keluarga (X) terhadap variabel kenakalan remaja (Y) adalah tidak linear.

\section{Selanjutnya, peneliti melakukan uji}

korelasi antara ketidak harmonisan dengan

kenakalan remaja dengan aplikasi SPSS 25.0

Tabel 2. Correlation is significant at the 0.05 level (2-tailed)

\begin{tabular}{|cc|c|c|}
\hline \multirow{2}{*}{$\begin{array}{c}\text { Ketidakharmonisan } \\
\text { Keluarga }\end{array}$} & $\begin{array}{c}\text { Pearson } \\
\text { Correlation } \\
\text { Sig. (2- } \\
\text { tailed) } \\
\text { Keluarga }\end{array}$ & 1 & $.304^{*}$ \\
& $\mathrm{~N}$ & 51 & .030 \\
Kenakalan Remaja & $\begin{array}{c}\text { Pearson } \\
\text { Correlation } \\
\text { Sig. (2- } \\
\text { tailed) } \\
\mathrm{N}\end{array}$ & $.304^{*}$ & 1 \\
\hline
\end{tabular}

for Windows sebagai berikut.

disimpulkan bahwa tidak ada pengaruh yang terlalu besar antara ketidakharmonisan 
DIEGESIS: Jurnal Teologi

Volume 6 No. 2, Agustus 2021.

keluarga terhadap kenakalan remaja di Masterplan youth GBI Eben Haezer.

Tabel 3. Interval Koefisien

Berdasarkan tabel di atas maka ditemukan koefisien korelasi antara $\mathrm{X}$ terhadap Y sebesar 0,304 termasuk dalam kategori sangat rendah. Jadi, dapat disimpulkan bahwa tidak ada pengaruh yang terlalu besar antara ketidakharmonisan

\begin{tabular}{|c|c|}
\hline $\begin{array}{c}\text { Interval } \\
\text { koefisien }\end{array}$ & $\begin{array}{c}\text { Tingkat } \\
\text { hubungan }\end{array}$ \\
\hline $\mathbf{0 . 0 0}-\mathbf{0 . 1 9 9}$ & Sangat Rendah \\
\hline $0.20-0.399$ & Rendah \\
\hline $0.40-0.599$ & Sedang \\
\hline $0.60-0.799$ & Kuat \\
\hline $0.80-1.00$ & Sangat kuat \\
\hline
\end{tabular}

keluarga terhadap kenakalan remaja di Masterplanyouth GBI Eben Haezer.

Jika koefisien korelasi dikuadratkan maka diperoleh hasil koefisien determinasi sebesar 0,092 atau 9,2\% artinya pengaruh antara $\mathrm{X}$ terhadap $\mathrm{Y}$ berdasarkan varians (koefisien determinasi) sebesar 0,092 atau $9,2 \%$, yang disebut sebagai pengaruh murni. Hal ini menunjukkan bahwa pengaruh Ketidakharmonisan Keluarga memberikan kontribusi sebesar 9,2\% terhadap Kenakalan Remaja dan sisanya dipengaruhi oleh faktor lain.
Kontribusi variabel $\mathrm{X}$ terhadap variabel $Y$ secara teoritis seharusnya memiliki pengaruh yang besar, namun dalam hal ini kontribusi hanya didapat sebesar 9,2\% saja. Berarti ada faktor lain di luar model ini yang tidak teliti oleh penulis misalnya faktor lingkungan, faktor individu, dan faktor ekonomi.

\section{Koefisien Korelasi Uji T Regresi Liniear Sederhana}

Tabel 4. Coefficients ${ }^{\mathrm{a}}$

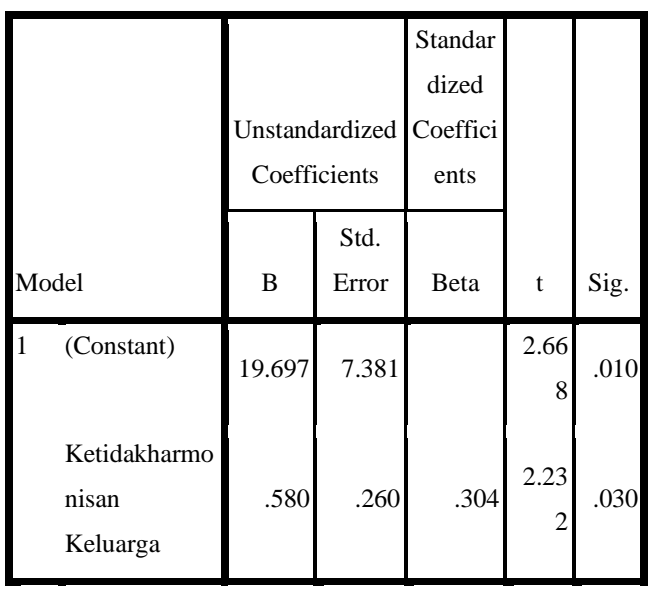

a. Dependent Variable:

Kenakalan Remaja

Hasil perhitungan menggunakan SPSS 16 for Windows diketahui bahwa harga beta nol 19,697 (a) dan harga beta satu (b) adalah 0,580, maka persamaan regresi antara ketidakharmonisan keluarga terhadap kenakakalan remaja dapat disusun sebagai berikut: $\hat{\mathbf{Y}}=\mathbf{1 9 , 6 9 7}-\mathbf{0 , 5 8 0} \mathrm{X}$

Yang artinya apabila variabel ketidakharmonisan keluarga (X) ditingkatkan satu tingkat, maka kenakalan remaja (Y) juga naik satu tingkat sebesar 
0,209 pada konstanta 29,924, oleh karena itu keharmonisan keluarga perlu ditingkatkan lagi agar kenakalan remaja tidak semakin meningkat.

\section{Pembahasan}

Dari analisis uji hipotesis disimpulkan bahwa tidak terdapat hubungan positif dan signifikan antara ketidakharmonisan keluarga terhadap kenakalan Remaja di GBI Eben Heazer. Dari hasil penelitian ini dapat disimpulkan bahwa tidak terdapat pengaruh yang positif dan signifikan antara ketidakharmonisan keluarga terhadap kenakalan remaja yang bersifat rendah pengaruhnya. Pengaruhnya sebesar 0,092 menunjukkan bahwa tidak terlalu besar pengaruh antara ketidakharmonisan keluarga terhadap kenakalan remaja di Masterplan Youth GBI Eben Haezer sebesar 9,2\% dan sisanya ditentukan oleh variabel lainnya.

Hasil analisis uji hipotesis disimpulkan bahwa tidak terdapat hubungan dan signifikan antara ketidakharmonisan keluarga terhadap kenakalan remaja atau penyimpangan sosial-spiritual di Masterplan Youth GBI Eben Haezer dengan nilai kontribusi sebesar 9,2\%. Di dalam penelitian ini, ditemukan bahwa Ketidakharmonisan keluarga tidak terlalu berpengaruh secara linieritas terhadap kenakalan remaja di Masterplan Youth GBI Eben Haezer. Ketidakharmonisan keluarga tidak memberikan pengaruh yang besar terhadap kenakalan remaja di kalangan Youth Masterplan GBI Eben Haezer karena kenakalan remaja juga bisa saja dipengaruhi oleh oleh faktor lain, seperti kebutuhan fisik maupun psikis anak-anak remaja yang tidak terpenuhi, keinginan dan harapan anak-anak tidak bisa tersalur dengan memuaskan (Een et al., 2020).

Apabila banyak kebutuhan anak remaja yang tidak tepenuhi anak akan merasa bahwa orangtuanya tidak peduli dan tidak memperhatikannya, sehingga anak akan berusaha dengan cara apapun demi memenuhi apa yang menjadi kebutuhan dirinya, dan remaja akan merasa puas ketika ia sudah mendapatkan semuanya itu (Amalia, 2011). Lain halnya dengan (Janesari, 2009) berpendapat bahwa kenakalan remaja dapat ditinjau dari beberapa faktor yaitu, faktor keturunan, lingkungan, keluarga, urbanisasi dan pengangguran. Meskipun kenakalan remaja bukan faktor biologis, tetapi faktor keturunan juga sangat berpengaruh. Faktor keturunan yang dimaksud adalah warisan yang dimiliki sehingga berasal dari dalam individu itu sendiri. Seperti keluarga yang buruk sebagai akibat lemah pikiran, penyakit 
syaraf, sehingga remaja kurang bisa menyesuaikan diri, kurang dapat menghargai nilai-nilai hidup yang baik dan yang lain mungkin memiliki tenaga yang melebihi anak-anak remaja pada umumnya sehingga terlihat sangat aktif dan terlihat seperti ingin berkelahi.

Terhadap permasalahan ini, gereja mesti melakukan upaya konkret yang implikatif dalam laku spiritualitas remaja, khususnya Youth Masterplan GBI Eben Heazer. Karena itu, gereja harus mampu membuat ibadah yang relevan untuk dapat menyampaikan kebenaran Firman Tuhan yang mendarat (Untung et al., 2021). Pendidikan iman yang kreatif dan mentransformasi para anggota pemuridan (Sirait, 2016). Khotbah yang di sajikan juga mesti kreatif (Christi, 2018). Disisi lain, pemaksimalan fungsi keluarga dalam segala aspek menjadi penting untuk diperhatikan dan diterapkan agar tidak terjadi lose value iman Kristen (Purim Marbun, 2020).

\section{SIMPULAN}

Variabel ketidakharmonisan keluarga dan kenakalan remaja keduanya tidak ada pengaruh yang terlalu besar. Artinya ketidakharmonisan keluarga bukan penyebab utama kenakalan remaja yang terjadi di Masterplan Youth GBI Eben Haezer, dan ada faktor lain yang menjadi penyebab kenakalan remaja, seperti dari faktor lingkungan, psikis yang tidak terpenuhi, pengangguran atau individu itu sendiri.

Tidak adanya hubungan positif dan signifikan antara Ketidakharmonisan Keluarga terhadap Kenakalan Remaja di Masterplan Youth GBI Eben Haezer. Hasil analisis menunjukkan bahwa didapatkan rxy sebesar 0,304 dengan interpretasi bahwa korelasi variabel Ketidakharmonisan Keluarga tidak memberikan pengaruh terhadap Kenakalan Remaja adalah 0,092 atau 9,2\% dan sisanya ditentukan oleh variabel lainnya yang tidak dijadikan variabel dalam penelitian ini. Hal ini menunjukkan Ketidakharmonisan Keluarga tidak memberikan pengaruh yang kuat terhadap Kenakalan Remaja di Masterplan Youth GBI Eben Haezer.

\section{DAFTAR PUSTAKA}

Amalia, L. (2011). Dampak Ketidakhadiran Ibu Sebagai Tenaga Kerja Wanita (TKW) Terhadap Perkembangan Psikologis Remaja. Kodifikasia, 5(1), 118.

Amos Hosea. (2019). Karakteristik Pendidikan Iman dalam

Pentakostalisme. Diegesis: Jurnal Teologi, $\quad 4(2), \quad 51-57$. 
https://doi.org/10.46933/dgs.vol4i25157

Aviyah, E., \& Farid, M. (2014). Religiusitas, Kontrol Diri dan Kenakalan Remaja. Persona:Jurnal Psikologi Indonesia, $3(02)$, 126-129. https://doi.org/10.30996/persona.v3i02. 376

Benyamin, P. I., Sinaga, U. P., \& Gracia, F. Y. (2021). Penggunaan "Platform" Digital pada Pembelajaran Pendidikan Agama Kristen di Era Disrupsi. REGULA FIDEI: Jurnal Pendidikan Agama Kristen, 6(1), 60-68.

Christi, A. M. (2018). Homiletika: Cara Menyusun dan Menyampaikan Khotbah yang Inspiratif. STT Bethel Indonesia.

Cipta, H. (2017). Dampak Perceraian Terhadap Kenakalan Remaja. Edugama: Jurnal Kependidikan Dan Sosial Keagamaan, 3(2), 88-103. https://doi.org/10.32923/edugama.v3i2. 724

Een, Tagela, U., \& Irawan, S. (2020). Jenisjenis Kenakalan Remaja dan Faktorfaktor yang Mempengaruhi di Desa Merak Rejo Kecamatan Bawen Kabupaten Semarang. Jurnal Bimbingan Dan Konseling Terapan, 4(1), 119-130.

Hadisuprapto, P. (2010). Delinkuensi Anak
Pemahaman dan Penanggulangannya. Selaras.

Hidajahturrokhmah, N., Kemuning, D. R., Rahayu, E. P., Araujo, P. A., Taqwim, R. A., \& Rahmawati, S. (2018). Sosialisasi HIV Atau AIDS Dalam Kehamilan Di Rt 27 Rw 10 Lingkungan Tirtoudan Kelurahan Tosaren Kecamatan Pesantren Kota Kediri. Journal of Community Engagement in Health, $\quad 1(1), \quad$ 14-16. https://doi.org/10.30994/10.30994/vol1 iss $1 \mathrm{pp} 16$

Janesari, O. (2009). Persepsi Remaja tentang Penyebab Perilaku Kenakalan Remaja. Universitas Sanata Dharma.

Johni Hardori. (2014). The Lost of Pastoral Ministry. In Reaffirming our Identity (p. 285). STT Bethel Indonesia.

Nadya Paramitha, Nuraeni, N., \& Setiawan, A. (2019). Sikap Remaja Yang Mengalami Broken Home: Studi Kualitatif. Jmcrh, 3(3), 137-149.

Noegroho, E. (2016). Studi Kasus Perilaku Delinkuen dalam Aspek Seksual di Jatinegara, Jakarta Timur dalam Konteks Implementasi Sistem Hukum dan Kebijakan Pemukiman. Indonesian Journal of Criminology, 12(1), 27-40.

Pakpahan, G. K. R. . (2020). Karakteristik Misi Keluarga Dalam Perspektif 
Perjanjian Lama. VOX DEI: Jurnal Teologi Dan Pastoral, 1(1), 16-36.

Purim Marbun. (2020). Optimalisasi Fungsi

Rumah Sebagai Tempat Pembinaan Warga Gereja di Masa Pandemi Covid19. Diegesis: Jurnal Teologi Kharismatika, 3(1), 26-43.

Puslidatin. (2019). Penggunaan Narkotika di

Kalangan Remaja Meningkat. Badan Narkotika Nasional RI.

Rahmajati, E. (2018). Kenakalan Remaja Ditinjau dari Elemen Ikatan Sosial. Universitas Muhammadiyah Surakarta.

Salman, I., Benyamin, P., \& Wartoni, W. (2021). Monitoring Model and Evaluation of ICT Utilization in The New Normal Era in Distance Learning in Madrasah. 1-8. https://doi.org/10.4108/eai.11-112020.2308302

Sirait, J. E. (2016). Pendidik Kristen Profesional, Inspiratif Dan Menarik. REGULA FIDEI: Jurnal Pendidikan Agama Kristen, 1(1), 33-62.

Sirait, J. E. (2021). Persepsi Pendidik Agama Kristen mengenai Pemicu Juvenile Delinquency di Indonesia. SIKIP: Jurnal Pendidikan Agama Kristen, 2(1), $1-15$. https://doi.org/10.52220/sikip.v2i1.77

Sugiyono. (2013). Metode Penelitian
Pendidikan Pendekatan Kuantitatif, Kualitatif, Dan $R \& D \quad$ (19th ed.). Alfabeta.

Sumara, D., Humaedi, S., \& Santoso, M. B. (2017). Kenalakan Remaja dan Penanganannya. Jurnal Penelitian \& PPM, 4(2), 346-353.

Trisna, R. P. (2016). Peranan Orang Kristen dalam Kehidupan Bernegara. In Bergereja dalam Bingkai Kebangsaan. STT Bethel Indonesia.

Untung, N., Tanonggi, R. O., \& Pekuwali, J. R. (2021). Komsel Pemuridan Kreatif Pemuda GBI Bukit Sion. Jurnal PKM Setiadharma, 1(1), 91-99.

Winurini, S. (2018). Remaja dan Perilaku Berisiko terhadap Minuman Keras (MIRAS) Oplosan. Info Singkat Bidang Kesejahteraan Sosial, 10(8), 13-18.

Zakiyyah, M. (2019). Pengaruh Kenakalan Remaja Terhadap Tingkat Kecemasan Orang Tua di Kecamatan Gending Kabupaten Probolinggo. JI-KES (Jurnal Ilmu Kesehatan), 3(1), 19-23. https://doi.org/10.33006/ji-kes.v3i1.124 Zaluchu, S. E. (2020). Strategi Penelitian Kualitatif dan Kuantitatif Di Dalam Penelitian Agama. Evangelikal: Jurnal Teologi Injili Dan Pembinaan Warga Jemaat, $\quad 4(1), 28$. https://doi.org/10.46445/ejti.v4i1.167 